\title{
Les modalités de production des morales politiques : étude comparative des assises des régimes politiques de la IIIe République et de l'Empire japonais (1868-1914)
}

Doctorat en science politique, sous la direction de Pierre Birnbaum, Université Paris I Panthéon-Sorbonne, soutenu le 15 octobre 2010.

Yusuke Inenaga

\section{(2) OpenEdition}

Édition électronique

URL : http://journals.openedition.org/assr/24587

DOI : $10.4000 /$ assr.24587

ISSN : $1777-5825$

Éditeur

Éditions de l'EHESS

Édition imprimée

Date de publication : 30 décembre 2012

Pagination : 309-358

ISSN : 0335-5985

Référence électronique

Yusuke Inenaga, "Les modalités de production des morales politiques : étude comparative des assises des régimes politiques de la Ille République et de l'Empire japonais (1868-1914) », Archives de sciences sociales des religions [En ligne], 160 | octobre-décembre 2012, mis en ligne le 14 mars 2013, consulté le 21 avril 2019. URL : http://journals.openedition.org/assr/24587

Ce document a été généré automatiquement le 21 avril 2019

(c) Archives de sciences sociales des religions 


\section{Les modalités de production des morales politiques: étude comparative des assises des régimes politiques de la IIIe République et de l'Empire japonais (1868-1914)}

Doctorat en science politique, sous la direction de Pierre Birnbaum, Université Paris I Panthéon-Sorbonne, soutenu le 15 octobre 2010.

\section{Yusuke Inenaga}

1 En comparant les morales politiques qui s'élaborent dans la vie collective pendant la période 1868-1914, cette thèse se propose de rendre compte d'un enjeu crucial, lié à la formation de la cohésion sociale et à la mise en place de l'obéissance aux normes qui, toutes deux, prennent place pendant l'étape de consolidation de la III ${ }^{e}$ République en France, et de l'Empire japonais (consolidation qui s'appuie sur trois piliers: administration agricole, éducation publique et conscription universelle).

2 Pour élucider le phénomène que constitue la production d'une morale dans la vie politique, ce travail se consacre à la compréhension des corrélations qui se créent entre un régime politique et une croyance dans la dimension du pouvoir d'État. La méthodologie de cette thèse croise deux perspectives, historique et comparative, et l'analyse critique des textes à vocation éducative (manuels scolaires, programmes et discours gouvernementaux, ouvrages intellectuels). Par ailleurs, pour éviter une analyse schématique des modèles qui reflètent notamment le fonctionnement des institutions - la famille, l'école publique, l'Église catholique et les sanctuaires shintoïstes, etc. -, il est indispensable de construire des concepts typologiques: normes féodales et normes civiques, sacré théocratique et sacré laïque, etc., en considérant la tension entre l'individu et les contraintes collectives que créent le contrôle autoritaire et la conformité aux règles traditionnelles. 
3 Plusieurs études des années 1960 ont exploré la sociologie historique comparée en prenant pour objet les pays occidentaux et le Japon. Mais les recherches récentes restent relativement rares, malgré l'intérêt d'une telle démarche pour la compréhension du contexte de la modernisation et de la démocratisation. C'est pourquoi ce travail est le reflet d'efforts poursuivis pour aller au-delà des études américaines de cette époque, en appliquant les résultats de la sociologie politique française.

4 La thèse porte sur deux aspects : (1) l'industrialisation, (2) la défense de la patrie et son lien avec la sensibilité morale d'autre part.

5 La première partie consacre deux chapitres à la transformation de l'environnement social dans la société agraire en soulignant la «question sociale». Elle s'attache tout particulièrement à montrer l'importance du rôle de l'éducation morale dans le développement de l'industrialisation. La recherche vise en effet à comparer les remèdes proposés pour freiner l'exode rural et l'abandon de la terre, en France et au Japon. À partir d'une perspective comparative orientée vers la survivance des normes féodales relatives au lien familial et, notamment, vers le sentiment d'appartenance à la terre, ce travail constate que, malgré la différence des régimes politiques, l'État républicain et l'État impérial ont, depuis 1881, chargé leurs ministères de l'Agriculture respectifs d'intervenir dans l'état moral du peuple pour améliorer la situation agricole. Les républicains, par exemple (Léon Bourgeois, Jules Ferry, Léon Gambetta et Jules Méline...), ont tenté d'assurer les droits individuels en terme de propriété foncière, à tous les paysans. Ils envisagent ainsi d'émanciper en quelque sorte la dignité de l'individu, qui reste compatible avec la dette sociale, tout en évitant un individualisme sans limites. Pour eux, la propriété de la terre ne provient plus de l'autorité religieuse attachée à l'Église catholique, mais est affirmée par des catégories juridicopolitiques soumises à la loi commune. L'étude a également montré la similitude de la vision du catholicisme conservateur français (Louis de Bonald, Mgr Dupanloup, Mgr Freppel et Joseph de Maistre) et de celle du néo-confucianisme japonais (Nagazane Motoda et Tôju Nakae), en identifiant deux modalités traditionnelles du respect de la piété filiale et du respect du pays natal. Étant donné l'interaction étroite entre l'autorité religieuse et l'exclusion des non-croyants, des étrangers et des «déviants " par rapport à la « religion d'État », on pourrait, en montrant l'analogie avec les conservateurs catholiques, définir l'encouragement prodigué aux normes féodales par l'État impérial comme un despotisme religieux, qui s'appuie sur le sentiment du devoir à l'égard du maitre ou du grand propriétaire, sur le culte des ancêtres, ainsi que sur la haine de la différence individualiste. Dans le cas des républicains, en revanche, l'État laïque manifeste un certain antagonisme à l'égard de la féodalité agricole: il envisage de détruire la contrainte traditionnelle qui est d'abord cléricale.

6 La seconde partie comporte trois chapitres. Pour définir un critère comparatif aidant à préciser la nature de l'articulation entre éducation morale et service militaire, la thèse aborde le concept de citoyenneté en mettant l'accent sur le mode d'appartenance à l'espace public. Bien que la perspective comparatiste, lorsqu'elle met en regard une civilisation chrétienne et une civilisation confucéenne, doive distinguer les connotations de sens, par exemple, la signification de certains concepts comme la «croyance», le " public » et le « civique » dans le milieu asiatique, il est apparu nécessaire d'inscrire la question de la citoyenneté dans la problématique du nationalisme. L'éducation obligatoire et gratuite en France est instaurée en 1882, tandis qu'au Japon elle est établie en 1900. Dans les manuels scolaires occidentaux reflétant la morale chrétienne, les 
traducteurs japonais ont modifié le sens moral et religieux ; ils ont par exemple donné un contenu différent aux mots «Ciel» et "Créateur» et ont exalté la clémence de l'empereur et la soumission volontaire à la divinité shintoïste. Pour les monarchistes japonais, l'appartenance à la patrie est naturelle et tous les membres de la communauté politique se rattachent à l'autorité divine et transcendante dans le culte de l'empereur.

7 Si l'on compare la figure religieuse de l'empereur à la construction de monuments commémoratifs, dans le cadre républicain, en France, monuments voués aux soldats morts de même que l'organisation des cérémonies civiques, on constate la mise en évidence d'un point de dissemblance en matière d'obligation morale-religieuse. De fait, pour les républicains, à la différence de ce qui existe dans l'Empire japonais, le service militaire n'est plus attaché à l'autorité religieuse ni à une loyauté, mais s'appuie sur l'autodétermination et la compassion séculière entre les citoyens. C'est-à-dire que, dans la position républicaine, l'expérience humaine forme l'appartenance à la patrie, dès lors qu'est supposée la liberté de conscience dans la société démocratique. En ce sens, on pourrait considérer que, pour les républicains, l'appartenance à la patrie est artificielle et non naturelle et que l'accent est mis sur l'obligation morale-scientifique. Cependant, il ne faut pas négliger la production du sacré qui représente le foyer de la communauté politique dans les deux pays. Au Japon, les responsables de l'État ont envisagé d'éduquer chaque enfant pour former un "soldat-impérial», en installant un personnage fictif, le fondateur de l'État, le premier empereur, Jimmu, intronisé en 660 av. J.-C., dans le cadre de l'éducation morale et de la fête nationale. Ainsi, dans leur tentative de déification de l'empereur, ils ont cherché à attribuer le sacré théocratique à l'empereur Meiji pour consolider le régime politique au nom de la pureté du sang royal. De leur côté, en France, les républicains ont associé le drapeau tricolore à la fête républicaine et l'ont considéré comme l'emblème de la nation, emblème chargé de cristalliser l'intégrité morale. La thèse propose de définir le drapeau tricolore comme le sacré laïque chargé d'assurer l'appartenance à la patrie. Chaque enfant devient, à travers l'incarnation du culte du drapeau, le « soldat-citoyen » qui se sacrifie pour sa patrie. C'est pourquoi le fils du Ciel et le morceau d'étoffe aux trois couleurs peuvent être considérés comme une institution symbolique de l'identité nationale, associée à la formation de l'esprit de sacrifice dans la sensibilité morale du peuple.

8 Pour conclure, l'analyse des discours politiques et du contenu des manuels de morale en usage dans les écoles primaires montre l'orientation symbolique de deux sacrés théocratique (l'empereur) et laïque (le drapeau tricolore) - chargés de fédérer la communauté politique. Dans la morale ethnonationale du Japon, la provenance et le culte des ancêtres sont inséparables de la manière traditionnelle de mesurer la distance qui sépare le médiocre du sublime, c'est-à-dire de la sensibilité morale sur laquelle les nationalistes s'appuient pour faire l'éloge de l'acte de sacrifice, mis au service de la patrie. L'alliance entre l'État-caserne et la religion nationale y est ainsi très éloignée de l'histoire de l'humanité dont la citoyenneté individualiste pourrait être l'incarnation à travers la solidarité sociale. Dans la morale civique, en France, l'État républicain est un État fort qui ne fait reposer aucune vue particulière sur les conditions de l'existence humaine. En s'opposant à toute servitude psychique à l'égard de l'autorité morale-religieuse, nécessaire, pour les conservateurs japonais, à la cimentation du sentiment national, les tendances de l'État républicain qui se déclarent hostiles à la croyance traditionnelle et s'appuient sur l'idéal de sécularisation de l'espace politique se situent dans un cadre foncièrement défavorable à la culture nationaliste. Ainsi, dans le régime républicain, 
l'individu n'est pas au service de l'État, mais l'État, en revanche, peut être mis au service de l'individu qui partage avec ses concitoyens la liberté de conscience et l'empathie civique avec autrui.

\section{AUTEUR}

\section{YUSUKE INENAGA}

yuinenaga@gmail.com 